\title{
Historias escolares y relatos de estudiantes del Profesorado de Inglés: Amor por la docencia
}

School stories and stories of students at the English Teaching Program:

Love for teaching

\section{Volumen 19, Número 3 \\ Setiembre-Diciembre \\ pp. 1-33}

Silvia Adriana Branda

Luis Gabriel Porta

Citar este documento según modelo APA

Branda, Silvia Adriana y Porta, Luis Gabriel. (2019). Historias escolares y relatos de estudiantes del Profesorado de Inglés: Amor por la docencia. Revista Actualidades Investigativas en Educación, 19(3), 1-33. Doi. 10.15517/aie.v19i3.38622 


\title{
Historias escolares y relatos de estudiantes del Profesorado de Inglés: Amor por la docencia \\ School stories and stories of students at the English Teaching Program: Love for teaching
}

\section{Silvia Adriana Branda ${ }^{1}$ Luis Gabriel Porta²}

Resumen: El presente artículo se gesta en el marco de una investigación mayor en el Grupo de Investigación en Educación y Estudios Culturales de la Universidad Nacional de Mar del Plata, Argentina, finalizada en el año 2017. El objetivo principal fue interpretar, a partir de las biografías escolares de estudiantes del Profesorado de Inglés, las enseñanzas que dejaron su huella y se manifiestan presentes en las prácticas iniciales, más precisamente en el momento de realizar sus Residencias Docentes II. Con el fin de explorar las huellas docentes en toda su variedad y complejidad, nos inclinamos por un enfoque cualitativo y adoptamos una perspectiva interpretativa y narrativa. Utilizamos variados instrumentos de recolección de datos que nos permitieron abordar las biografías del grupo de participantes desde diferentes perspectivas: entrevistas biográficas y focales, registros etnográficos, entrevistas rápidas y observación documental. De esta manera, la investigación realizada nos permitió identificar experiencias que dejaron su huella y se hicieron presentes en las prácticas pre-profesionales desde el intelecto y el afecto y nos posibilitó generar dos grandes categorías: amor por la docencia y gusto por el idioma inglés. En esta ocasión, nos concentraremos en la primera. Las líneas de profundización situadas de esta investigación nos hablan de los sentidos de la experiencia en términos de las actitudes afectivas e intelectuales recuperadas a partir de las trazas que dan cuenta de recuerdos, deseos y emociones que constituyen las huellas de lo que hoy son como docentes. Los resultados que de aquí se desprendieron podrían ser transferidos a distintos contextos de formación del profesorado y tener un alcance glocal que permita colaborar en la construcción del perfil profesional de futuras personas docentes.

Palabras clave: formación docente, educación, biografía, aprendizaje de inglés

\begin{abstract}
This article originates in the framework of a major research carried out by the Research Group in Education and Cultural Studies, National University of Mar del Plata and finished in 2017. Its main objective was: to interpret, from the school biographies of students of the English Teaching Program the teachings that left their marks and are present in the initial practices, more precisely at the time of carrying out their Teaching Residences II. To explore the traces of teachers in all their variety and complexity, we adopted an interpretative narrative perspective. We collected data using instruments that allowed us to approach the biography of the participants from different perspectives: biographical and focal interviews, ethnographic record, flash interviews and observations. In this way, the research conducted allowed us to know the teachings that left their mark and are present in pre-professional practices from intellect and affection allowing us to create two broad categories: love for teaching and pleasure for the English language. This time we will concentrate on the first one. The deepening lines that define this research tell us about the senses of experience in terms of the affective and intellectual attitudes recovered from the traces that give account of memories, desires and emotions that constitute teachers today. The results of this research can be transferred to different contexts of teacher education having a glocal scope collaborating in the construction of the professional profile of future teachers.
\end{abstract}

Key words: teacher education, education, biography, english learning

\footnotetext{
1 Profesora de la Universidad Nacional de Mar del Plata, Argentina.

Dirección electrónica: branda.silvia@gmail.com

2 Profesor de la Universidad Nacional de Mar del Plata, Argentina.

Dirección electrónica: luisporta510@gmail.com
}

Artículo recibido: $1^{\circ}$ de abril, 2019

Enviado a corrección: 20 de junio, 2019

Aprobado: 5 de agosto, 2019 


\section{Introducción y planteamiento del problema ${ }^{3}$}

Iniciaremos este artículo con algunos interrogantes que nos van a guiar en el recorrido que aquí realizaremos. Quiénes transitamos el profesorado ¿nos detenemos a pensar en las marcas que dejaron los maestros y las maestras en nuestras vidas? Probablemente no lo hacemos muy a menudo o tal vez nunca. Quizás la mayor parte de nosotros apenas recuerda algunos nombres de docentes que tuvimos a lo largo del recorrido escolar, a menos que, de forma consciente, indaguemos acerca de cómo impactaron en nuestra formación. Tal vez, algunos podríamos recordar a uno o dos maestros o maestras excepcionales, quienes gestaron un cambio real en nuestras vivencias y en algunos casos, hasta podríamos recordar las palabras exactas que provocaron estos cambios. Pero ¿acaso recordamos estas experiencias en forma frecuente? Si bien somos portadores de las marcas que nos dejaron nuestros docentes, cuando procuramos identificar cuáles son o ponerlas de manifiesto, no somos capaces de hacerlo.

Las historias vividas en la escuela constituyen, para quienes se dedican a enseñar, una fuente de experiencia con rasgos que luego se reflejan en la práctica, sobre todo en docentes nóveles, quienes, ante la incertidumbre y la ansiedad en su entrada al aula, se basan en vivencias previas como estudiantes para configurar sus propios estilos y estrategias de enseñanza (Hargreaves, 1996). Son numerosas las investigaciones que han resaltado la importancia de la biografía escolar previa para quienes enseñan, en particular, cuando dan sus primeros pasos en la docencia. Por un lado, ya en 1975, Lortie señalaba que la biografía escolar es el elemento clave para entender la socialización profesional. Sus reflexiones en Schoolteacher (1975) apuntan a las marcas que la vivencia escolar previa deja en quienes ejercen la docencia. Ese aprendizaje anterior a la etapa de preparación profesional, despojado de todo lenguaje técnico, transcurre durante muchos años en los que se está en contacto con la escuela y deja su influencia en quienes luego se dedican a enseñar. Por otro lado, Alliaud (2010) sostiene que el pasaje prolongado por la escuela forma y actúa en los sujetos a modo de esquemas, configurando las prácticas y representaciones del presente. Por lo tanto, en la escuela vivida podrían encontrarse las semillas de lo que luego se produce y reproduce en la práctica profesional.

3 Esta investigación fue realizada por el Grupo de Investigación en Educación y Estudios Culturales de la Universidad Nacional de Mar del Plata, Argentina, y con los resultados producto de una tesis doctoral para el Doctorado en Humanidades y Artes. Mención Ciencias de la Educación de la misma universidad. 
Consideramos que la biografía escolar tiene suma relevancia en la construcción de la profesión docente. De esta manera, realizamos una investigación que nos permitió centrarnos en aquellas buenas enseñanzas que dejan una fuerte impronta en un grupo de estudiantes del Profesorado de Inglés de la Universidad Nacional de Mar del Plata (en adelante UNMdP) que cursaban su Residencia Docente II durante un cuatrimestre. Este grupo de residentes, luego, consciente o inconscientemente, toman estas buenas enseñanzas al momento de realizar sus prácticas pre-profesionales, recreándolas dentro y fuera del aula. Buscamos categorías interpretativas vinculadas al origen mismo de las enseñanzas implícitas y explícitas, a los sujetos implicados y las características propias de las prácticas. Nos propusimos sacar a luz aquellas buenas prácticas heredadas interpelando la biografía de quienes estaban realizando sus Residencias Docentes porque consideramos que estas prácticas contribuyen a comprender el accionar profesional y alientan la intervención en los ámbitos de formación. Abordamos el pasado escolar reparando en la manera en que practicantes/residentes - estudiantes que realizan sus prácticas preprofesionales, términos que utilizaremos de manera indistinta en este artículo - rehacen, reconstruyen y reflexionan con imágenes presentes, sus experiencias escolares vividas atendiendo al significado que le atribuyen desde la perspectiva de su aquí y ahora.

Como formadores de docentes, nos hemos cuestionado siempre qué contiene la "mochila" que trae el alumnado a las prácticas, cómo se han formado en su paso por la universidad y si las decisiones que toman al momento de planificar o dar sus clases provienen de lo que se han apropiado en el cursado de las asignaturas del área o de las experiencias que emergen de sus biografías escolares. A fin de buscar respuestas a los interrogantes arriba planteados, diseñamos una investigación cuyo objetivo principal fue interpretar, a partir de las biografías escolares de estudiantes del Profesorado de Inglés de la Universidad Nacional de Mar del Plata, las enseñanzas que dejaron su huella y se hicieron presentes en las prácticas iniciales, más precisamente al momento de realizar sus Residencias Docentes II. De este objetivo general se desprendieron los siguientes objetivos específicos:

- Identificar, en la práctica pre-profesional del estudiantado, las enseñanzas que dejaron trazas sus trayectorias escolares.

- Indagar, a través del relato del grupo de residentes, cómo se manifiestan estas enseñanzas en su práctica.

- Analizar la impronta que deja la biografía escolar del estudiantado en sus prácticas preprofesionales. 
Cabe aclarar aquí que la investigación fue financiada con recursos de la Universidad Nacional de Mar del Plata. Desarrollaremos, a continuación, el marco de referencia que sustenta este artículo, para luego abordar los componentes metodológicos, los resultados y las conclusiones.

\section{Referente teórico}

En ocasiones quienes nos dedicamos a enseñar nos preguntamos por qué actuamos de tal o cual manera en la clase o fuera de ella al momento de planificar, y creemos que lo hacemos así por las concepciones epistemológicas subyacentes a nuestra disciplina. No obstante, hay otras cuestiones que van aún más allá y tienen que ver con las marcas que han dejado las enseñanzas que hemos recibido en nuestra trayectoria escolar, desde el inicio hasta nuestra formación de grado y posgrado. Nos proponemos entonces, indagar en las biografías escolares de estudiantes del Profesorado de Inglés rastros de las marcas que han dejado sus docentes, para poder así interpretar las prácticas pre-profesionales a través de las percepciones y significados producidos por las experiencias de las personas. De esta manera, decidimos abordar una investigación cualitativa con un enfoque interpretativo biográfico narrativo. A continuación, nos sumergiremos en un breve análisis que desarrolla la importancia de la narrativa en educación.

\subsection{La narrativa en educación: Un abanico de posibilidades que se abre}

Las experiencias pedagógicas, las historias escolares y los relatos de enseñanza que narran docentes en primera persona generan una fuente muy valiosa para conocer lo que hacen, piensan y sienten quienes habitan la escuela, porque al narrar se relatan los actos humanos y los sentimientos presentes en la vida de los involucrados. Está comprometido lo cognitivo, lo afectivo y la acción que se expresa por medio del relato y se convierte en un material pedagógico muy potente sobre el que se pueden diseñar y llevar a cabo dispositivos para desarrollo profesional de docentes, tanto durante su preparación inicial como durante la implementación de los distintos planes de capacitación. Polkinghorne adopta la siguiente posición: "Alcanzamos nuestra identidad y la idea de nosotros mismos por el uso de la configuración narrativa, y totalizamos nuestra existencia comprendiéndola como la expresión de una historia simple que se revela" (1995, p. 150).

Connelly y Clandinin (1990) afirman que la narrativa en la investigación educativa implica pensar que los seres humanos narran y viven existencias relatadas donde participan 
co-autoralmente y son a su vez personajes. Así, experimentar la narrativa implica explorar formas de vivenciar al mundo, las cuales comprenden tres dimensiones: la primera nos remite a la cualidad ontológica de la narrativa, es decir, al fenómeno relatado. La segunda nos dirige a su condición metodológica, es decir, considera a la indagación narrativa como metodología de investigación de corte cualitativo para abordar a los fenómenos contados. La tercera comprende el empleo de textos de campo narrativos, que han sido recogidos para investigar el fenómeno refiriendo a la materialidad de los relatos y a sus modos de conocerlos, no solo a técnicas de recolección (Connelly y Clandinin, 1990, 1994, 2006).

La historia de la propia vida suele ser un vehículo para tomar distancia de esa experiencia y así convertirla en un objeto de reflexión. Docentes que escapan momentáneamente del ajetreo de la vida del aula para explorar sus vidas y resignificar sus experiencias. Caporossi, (2009) y Bolívar, Domingo y Fernández (2001) han analizado este proceso argumentando que cuando entra en acción la reflexión surge la verdadera posibilidad de romper con nuestra visión de nosotros mismos y avanzar hacia otro lugar. Agregan que la entrevista interactiva sobre las autobiografías de docentes es una excelente vía hacia el cambio de actitud, y desde allí, hacia una suerte de emancipación de los trillados caminos de pensamiento acerca del propio trabajo.

El término emancipación implica tener una visión más crítica del lugar que ocupamos en la profesión y en la organización social de esta ${ }^{4}$ (Caporossi, 2009). Nuestra postura al respecto es que, explorar la propia vida como docente puede abrir vías novedosas para reconstruir formas de actuar y de ser en el aula, y a partir de allí, para repensar la propia práctica. Lo atrayente de las biografías es que, sin tener la necesidad de recurrir a leyes, podemos responder a la pregunta de por qué sucedió algo, ya que esta respuesta puede encontrarse en la conjunción de acontecimientos diferentes en cada historia (Bolívar et al., 2001).

El enfoque narrativo ha sido cada vez más utilizado en estudios sobre la experiencia educativa. En ciencias sociales, a partir de los años setenta, comenzamos a transitar un camino que abandona la mirada tradicional positivista y se dirige hacia una perspectiva interpretativa. De esta manera, incursionamos en un tipo de investigación que tiene un doble

\footnotetext{
4 En las últimas décadas del siglo $X X$ surge un pensamiento pedagógico que, en cierta manera, está caracterizado por su fe en la educación como proceso emancipador. Se trata de una práctica encaminada al logro de un mundo más justo y más humano, por su solidaridad con los grupos sociales más desfavorecidos y por su crítica tanto a las prácticas pedagógicas precedentes como a la realidad social y política en la que se lleva a cabo el proceso educativo
} 
rol: por un lado, se le da "la voz a los profesores y profesoras sobre sus preocupaciones y sus vidas" por el otro, "supone una fisura en los modos habituales de comprender e investigar lo social" (Bolívar et al., 2001, p. 55). Comenzamos con una idea revolucionaria que, de acuerdo con Bruner (1997), al teorizar sobre la práctica, debemos partir del saber popular que tienen los propios conocimientos implicados en enseñar y aprender. A su vez, si queremos entender cómo alguien piensa, actúa, siente, o cómo conoce lo que sabe, es preciso entrar en la dimensión individual de la vida no solo actual, sino retrospectiva, que ha configurado lo que es, cómo piensa y actúa.

En resumen, la indagación narrativa nos aproxima a las vidas en la educación en su temporalidad, su socialidad y su espacialidad. En en su metáfora de paisaje o landscape, Connelly y Clandinin (2006) nos hablan de space, place and time, y al ahondar en el término space hacen referencia a lo que ellos denominan sociability, es decir, a un espacio que lo ocupan personas y eventos que se entrelazan en las relaciones interpersonales. Optamos, en la investigación que enmarca este artículo, usar la traducción "socialidad" para refererirnos a sociability, y buscamos mantener el sentido que los autores desean otorgar. Necesitamos prestar atención a dichas existencias, no sólo por lo que cuentan sino por cómo y por qué lo relatan, lo vuelven a relatar y a revivir (Connelly y Clandinin, 1990, 1994, 2006).

\section{Metodología}

La investigación que alimenta este artículo se gestó en el marco de las residencias como dispositivo de práctica inicial, quienes participaron en ella estaban realizando sus prácticas pre-profesionales. En el análisis debimos recordar que estas se ven atravesadas indefectiblemente, por un lado, por el carácter evaluativo que, en términos de calificación, tiñe toda instancia (Edelstein, 2015); por el otro, por la presencia de otros -tutor, pareja pedagógica, profesor del curso e investigadora- ajenos al aula que, de alguna manera, condicionan al practicante. Las prácticas docentes en sí implican "poner el cuerpo; estar al frente, de frente, enfrente: sostener y sostenerse; exponer y exponerse a otros [...]" (Edelstein, 2015, p. 191), es así que provocan en los practicantes una gran sensación de vulnerabilidad.

\subsection{Enfoque}

Nuestro objetivo de estudio y la manera de interpelarlo nos permitió comprender un entramado de relaciones que muestra procesos de construcción de subjetividades 
individuales. En este sentido, examinamos esa urdimbre que se va tejiendo entre la dimensión personal y la profesional docente. Para ello realizamos una investigación de corte cualitativo con un enfoque interpretativo, entendido como un proceso de comprensión de las representaciones cercanas de los propios sujetos, lo cual necesita la configuración de una lectura de significados jugando entre lo general y lo particular; es decir, entre los detalles inmediatos y la teoría relevada. Asimismo, adoptamos una perspectiva narrativa. Desde que la investigación educativa sufrió su giro narrativo, se han comenzado a estudiar las vidas de docentes y estudiantes en las cuales se pondera el conocimiento acerca de las experiencias pasadas (Bruner, 1997). El material textual constituye aquí una fuente legítima de nuevos saberes sobre el mundo social. La conexión entre narrativas biográficas de futuros profesionales de la educación, ya en sus últimos años de carrera de grado, y el contexto sociocultural e institucional en el que se inscriben, tiene la pretensión de hacer posible que lo individual se torne colectivo.

\subsection{Participantes}

Inicialmente participó de la investigación el grupo completo de estudiantes que cursó la materia Residencia Docente II (última materia del Área de Formación docente) del Profesorado de Inglés de la UNMdP en el ciclo lectivo 2016. Comenzamos el trabajo de campo con el aporte de catorce relatos brindados por la totalidad del alumnado que estaba tomando la materia en ese ciclo. Solicitamos, mediante consentimiento informado, permiso para utilizar sus narrativas y el producto del análisis de los diferentes instrumentos en futuras publicaciones. En la medida que fuimos avanzando en la propuesta, el número se fue delimitando hasta llegar a nueve, que fueron quienes finalmente se involucraron, tanto en las entrevistas biográficas como en las focales. Si bien nuestra intención inicial fue contar con la totalidad del grupo de residentes desde el inicio al final del proceso de indagación; es decir, catorce estudiantes que estaban realizando las residencias en ese cuatrimestre, esto no fue posible debido a la escasa disponibilidad horaria durante la cursada de una materia que les demandaba mucho tiempo, tanto en la planificación como en el encuentro con los tutores y el dictado de las clases mismas. Respetamos su decisión de intervenir únicamente en la primera etapa de la investigación -relatos escritos- y continuamos el trabajo de campo con los nueve participantes que tuvieron la generosidad de brindar su tiempo para las entrevistas biográficas y focales. De esta manera, el grupo de participantes se redujo a nueve, con quienes finalmente co-construimos las nueve historias. En este trabajo se hace referencia 
únicamente a un grupo de historias que corresponde a quienes declararon sentir "amor por la docencia", es decir, cuatro participantes.

\subsection{Técnicas de recolección de datos}

Para concretar el objetivo de la investigación diseñamos y utilizamos distintos instrumentos de recolección de datos que compusieron los textos de campo: 14 relatos escritos - RE-, 9 entrevistas biográficas -EB-, 3 grupos/entrevistas focales -GF-, registro etnográfico -RET-, entrevistas flash -EF- y diferentes documentos: planes de clases -PC-, diarios de clase -DC- e informes finales -IF-.La interacción recursiva con los textos de campo nos permitió encontrar respuestas a los interrogantes que guiaban la investigación: ¿Cuáles fueron las buenas enseñanzas que han dejado su huella en la biografía de estudiantes del Profesorado de Inglés de la UNMdP?, ¿de qué manera el estudiantado caracterizó estas enseñanzas?, ¿cómo se manifestaron en sus prácticas iniciales? y ¿qué rasgos dejaron en sus biografías escolares? Seguidamente, describiremos cada uno de los instrumentos mencionados:

Relatos escritos: Solicitamos al grupo de participantes que narraran de manera escrita y guiados por cuatro ítems, experiencias de buena enseñanza que recuerdan de su biografía escolar. Así, la investigación narrativa, utilizando el relato escrito por los propios protagonistas, logra mostrar, sin la intervención de palabras ajenas, eso que sucede en especial en la formación docente. Los ítems que guiaron los relatos apuntaban a responder algunas preguntas y a relatar experiencias, a saber:

¿Cómo crees que influyó tu biografía escolar en tu práctica pre-profesional (Micro experiencias de enseñanza y Residencia Docente I)?

¿Consideras que tu biografía escolar contribuye en la formación de tu perfil profesional? Si es así ¿de qué manera?

¿Podrías identificar indicios de tu biografía escolar presentes en tus propias clases? ¿Cuáles?

Narra alguna experiencia de buena enseñanza que recuerdes de tu biografía escolar.

Entrevistas biográficas: Cada una fue realizada en un encuentro. Buscaron la comprensión de las perspectivas del grupo de informantes respecto de sus vidas, experiencias o situaciones, tal como las expresan con sus propias palabras. Siguieron el modelo de una conversación entre iguales en lugar de ser un intercambio formal de preguntas y respuestas. En esta investigación, la entrevista permitió el estudio de 
experiencias pasadas para así interpretar las representaciones y las prácticas residentes, ofreciendo información acerca de la toma de decisiones y de otros elementos condicionantes que moldean su desempeño en la enseñanza, dentro y fuera del aula. Según Taylor y Bogdan (2007) lo importante no es el número de entrevistados, sino el potencial de cada caso para ayudar en el desarrollo de comprensiones teóricas sobre lo que se estudiará. Estas entrevistas no apuntaron directamente a recrear los relatos anteriores, sino que buscaron complementarlos y contextualizarlos. La narración de las propias biografías escolares colaboró con este proceso de hacer presentes las concepciones subyacentes, para así poder trabajar sobre ellas.

Entrevistas focales: Apuntan a estudiar una experiencia muy concreta compartida por un grupo de personas, en este caso, se trató de aquellas enseñanzas implícitas y explícitas que dejaron sus trazas en la trayectoria escolar de estudiantes avanzados del Profesorado de Inglés. Consiste en reunir entre 5 y 15 personas para realizar una discusión de grupo (Yuni y Urbano, 2005) acerca de un tema. El que el equipo de investigación guía la charla teniendo en cuenta una serie de preguntas o temas a explorar (Yuni y Urbano, 2005). El objetivo es que el grupo se exprese de manera libre y espontánea sobre un tema en particular.

La entrevista focal tuvo ventajas muy provechosas en esta investigación en particular: el ambiente del grupo propició una atmósfera de seguridad en la que las personas participantes no sintieron presión al responder todas y cada una de las preguntas formuladas. Se logró un diálogo colaborativo abriendo un espacio para la reflexión. Asimismo, se realizaron tres entrevistas focales en las que participaron el grupo de 9 estudiantes que ya habían realizado las entrevistas biográficas.

Entrevistas flash: Las realizamos inmediatamente después de las clases que presenciamos. Fueron preguntas espontáneas que se generaron a partir de nuestra entrada al aula y del registro etnográfico; tuvieron la particularidad de ser rápidas, de pocos minutos. De esta manera, obtuvimos datos en torno a las decisiones tomadas por cada practicante durante la clase. Debido a que se realizaron en el tiempo inmediatamente posterior al acontecimiento de la clase, en el espacio mismo de la experiencia obtuvimos de manera natural, fresca y sencilla los testimonios que se desprendieron de decisiones pedagógicas y didácticas, así como también afectivas.

Observaciones: Se refieren a la inspección del investigador con sus propios sentidos, de las cosas o hechos de interés social. Se utilizan para examinar las fuentes donde se 
encuentran los hechos y datos objeto de estudio y también para registrarlos. Los datos se recogen de forma sistemática y no intrusiva. En esta investigación, realizamos observación presencial -las clases de cada practicante en la que concretamos el registro etnográfico- y documental-los planes, diarios de clases y los informes finales.

Planes de clase: Se trata de documentos escritos, tentativos en torno a lo que se va a enseñar. En ellos se plasman los datos de la institución, del curso, de cada practicante, los objetivos generales y específicos, las actividades planteadas y el tiempo estimado para cada una de ellas y la interacción que se propone en el aula. Se confeccionan, por un lado, para que cada residente tenga su clase armada, contemplando el contenido, las características del curso y de la institución, pero esto no implica que, por alguna razón -dudas que surgen en el momento, intereses particulares, interrupciones, etc.- no se pueda cambiar sobre la marcha el rumbo de lo planificado. Por otro lado, sirven de guía a quien observa la clase.

Diario de clase: Es un documento personal y autobiográfico de cada practicante que comparte con su pareja pedagógica y con su tutor o tutora. Es un registro escrito que contempla opiniones, interpretaciones, reflexiones e incluso sentimientos acerca de las clases. Permite documentar, mediante la observación, todo lo que sucede en el aula. Se torna más útil aun cuando las narrativas que en él se plasman son compartidas con otro, promoviendo así un debate reflexivo y una construcción de conocimiento colectiva. Se plasman en él tanto aspectos observables sobre lo que ocurrido en el aula, como también aquellos que no son percibidos a simple vista, como las emociones. En Residencia Docente II del Profesorado de Inglés de la UNMdP se lo utiliza como dispositivo de reflexión en la construcción del conocimiento profesional y como instrumento para el análisis de algunos aspectos teóricos, y en ocasiones intuitivos, que respaldan las decisiones que los residentes toman al momento de planificar y dar la clase.

Informe final: Se trata de un instrumento que permite analizar el recorrido vivido durante Residencia Docente II. Estos informes son confeccionados, al final de las prácticas, por el alumnado y compartidos con el grupo de tutores. Son reflexiones de cada estudiante plasmadas en relatos significativos y vivencias. Aluden a experiencias realizadas tanto dentro del ámbito escolar como fuera de Este, pero siempre vinculadas con sus prácticas. Expresan una memoria personal con relatos de lo vivido, valores, desafíos, dificultades y resultados; son de gran relevancia para apoyar el autoconocimiento. Este informe, que alienta a cada practicante a narrar sus valoraciones durante el proceso de residencia, le da un cierre a las prácticas. La escritura del informe final es otra instancia de reflexión sobre lo vivido, ya que 
invita a revisar sus anotaciones y a descubrir aquellos momentos que resultaron importantes en su residencia. De este modo, se abre la posibilidad de analizar sus clases y tener que ponerlas por escrito. Esto fomenta y potencia los procesos reflexivos que se generan en las prácticas.

Registro etnográfico: Fue el instrumento de recolección de información utilizado en forma permanente durante la observación de las prácticas en la investigación. Allí cobraron vida el lenguaje, el sistema de signos que representan los gestos, los silencios, las miradas, que constituyen, como dice García (2015), un complejo reticulado semiótico y comunicativo. Rockwell (2011) hace referencia a este tipo de registro para documentar lo no documentado en la realidad social - lo familiar, lo cotidiano, lo oculto, lo inconsciente - y, de esta manera, dejar testimonio escrito y público de lo sustantivo atendiendo a sus significados. Rockwell (2011) agrega que, a diferencia del saber pedagógico, el saber docente rara vez se documenta y por lo tanto, el registro etnográfico ofrece una manera de hacerlo visible y audible. Para este instrumento utilizamos un cuaderno en el que plasmamos aquellas cuestiones que no surgieron ni en los relatos escritos ni en las entrevistas, o aquellas que de alguna manera nos remitieron a lo relevado por los instrumentos anteriores y fueron producto de lo que sucedió en la clase o reflexiones en torno a ella. De esta forma, sistemáticamente tomamos nota y registramos, durante las clases observadas, la información relevante para la interpretación de las enseñanzas que dejaron su huella y se manifestaron presentes en las prácticas iniciales.

\subsection{Procesamiento y análisis}

En consonancia con las palabras de Bolívar et al., "la recogida de información de diferentes fuentes y momentos debe ser procesada y combinada para posibilitar una comprensión acertada" (2001, p. 263), cada uno de los instrumentos utilizados generó un aporte nuevo y validó el de los otros, permitiendo aclaraciones e interpretaciones más sustanciosas a través del proceso de cristalización. La construcción de conocimiento fue válida y posible a partir de la trama de relaciones intersubjetivas que brindaron los distintos instrumentos y que dieron lugar a la multiplicidad de voces.

Es así que las diversas tareas que realizamos durante el proceso fueron agregando validez a la investigación. Grabamos en audio las entrevistas biográficas, luego las transcribimos y las enviamos vía correo electrónico a cada participante para su lectura y validación de la información. Procedimos de la misma manera con las tres entrevistas 
focales. Luego, realizamos la lectura y análisis de todos los instrumentos que nos permitieron la co-construcción de las historias. Estas historias también fueron enviadas a sus co-autores y co-autoras, quienes tuvieron la oportunidad de leerlas y modificarlas en caso de ser necesario (en algunos casos agregaron información y en otros, solicitaron quitar datos que no deseaban hacer públicos). Al final de cada historia, solicitamos a cada participante que "selle" su co-autoría con una imagen, metáfora o poema que lo represente.

Durante todo el proceso de lectura y análisis, el dialogo vía correo electrónico con el grupo de participantes fue constante. Validaron los textos construidos por la investigadora dando lugar a una co-construcción de las historias y el posterior análisis horizontal de la información al momento de proceder con las conceptualizaciones. La utilización de los distintos instrumentos para la recolección de información con su multiplicidad de voces, sumado al diálogo permanente con el grupo de participantes generaron un relato polifónico que dio lugar a la saturación de la información en la búsqueda de respuestas a los interrogantes que guiaron todo el proceso.

Organizamos el análisis de los textos de campo en dos momentos, que no impiden el manejo recursivo de la información, por el contrario, favorecen el recorrido cíclico en la interpretación. En el primero trabajamos verticalmente con cada historia co-construida recurriendo a todos los textos de campo de cada participante. En el segundo, por medio de un análisis horizontal de cada instrumento, atravesado por los relatos del grupo de participantes, nos avocamos a la re-conceptualización de las biografías escolares en un paisaje común de socialidad temporalidad y espacialidad (Clandinin y Connelly, 1995) buscando responder las preguntas que guiaron la investigación.

Estos dos momentos representan la construcción narrativa densa y nos permiten hacer uso de la doble hermenéutica que da cuenta de la imbricación y de la interpretación que existe entre el saber científico y el saber común. Desde nuestra perspectiva interpretativa rescatamos la hermenéutica como comprensión de lo social, por lo tanto, en este análisis nos interesa otorgar significado e interpretar las experiencias humanas por medio de la interacción entre investigadores y participantes. Quienes reflexionan y hacen inteligible su mundo, lo significan y lo interpretan. Es así como damos un primer sentido en el análisis de las narrativas, por medio de una red de conceptos poderosos que se van entramando y articulando. Un segundo sentido es el que le otorgamos a través del análisis del relato extenso y co-compuesto originado en el primer momento. Finalmente, el tercer 
sentido es el que cada participante le da a su propia historia con su sello personal de poema, metáfora o imagen que lo representa.

\subsubsection{Primer momento: Las historias co-construidas}

Comenzamos nuestro análisis con la voz y los relatos del grupo de narradores para concentrarnos en sus propias historias, distanciándonos un poco del tradicional método orientado por el tema para el análisis del material cualitativo. Así, en lugar de ubicar los temas distintivos en la medida que transcurre la entrevista, escuchamos primero las voces que habitan cada narrativa. Presentamos nuestra co-construcción narrativa de los nueve relatos que surgen de las interacciones con el grupo de nueve participantes. Para coestructurar estas historias desentrañamos la trama, el tejido narrativo (Ricoeur, 2000) de cada una de ellas utilizando sus testimonios recopilados en las entrevistas biográficas y en las focales, en los relatos escritos, en los registros etnográficos, en las entrevistas flash, en los planes y en los diarios de clases de cada practicante. Inicialmente, reconocemos por un lado, cuatro practicantes que, al elegir el Profesorado de Inglés, deseaban ser docentes y tenían un gusto especial por la lengua inglesa y por el otro, a cinco que eligieron su carrera por amor al idioma, pero sin tener como meta final la docencia. Así se desprenden dos grandes categorías que enmarcan los dos momentos de análisis: el deseo de ser docente y huellas impregnadas por el idioma inglés.

En esta ocasión deseamos concentrarnos en el segundo momento y más precisamente en el grupo de participantes que optó por el Profesorado de Inglés por el deseo de enseñar, y su amor por la docencia. Cada uno eligió un nombre, ellos son: Joy, Marian, Mercedes y Vera. Así, sin necesidad de develar sus propios nombres, se sintieron a gusto para narrar sus experiencias.

\subsubsection{Segundo momento: Re-conceptualización de las biografías escolares en un} paisaje común de socialidades, temporalidades y espacialidades

Clandinin y Connelly (1995) aseguran que el conocimiento práctico personal docente se forma desde su experiencia pasada, en la mente y el cuerpo del presente y con los planes y acciones futuras de cada profesional. Agregan que el conocimiento docente está formado y expresado en el complejo contexto en que cada uno se desempeña. Ellos utilizan una metáfora para describir esta complejidad, que es la metáfora de paisaje (Clandinin y Connelly, 1995). Mediante esta metáfora desean representar el tiempo, el lugar y el espacio 
con una idea de expansión y con la posibilidad de que distintas personas, eventos y relaciones se involucren. Esto es, la relación entre personas, lugares y cosas representando un paisaje moral e intelectual. Pensar la vida como una historia es una forma potente de imaginar quiénes somos, dónde hemos estado y a dónde nos dirigimos.

Los relatos capturados en la secuencia de narrar expresan descubrimientos, anhelos, esperanzas, pasión, afán de superación, amor, afecto, sensibilidad, compromiso, reflexividad, espíritu de lucha, empatía, trabajo, antagonismos y búsqueda de cooperación. En este segundo momento reconfiguramos las historias del grupo de residentes a partir de los tres lugares interrelacionados en la narrativa: la temporalidad, la socialidad y la espacialidad, formando así un paisaje común. Realizamos numerosas lecturas a los textos de campo y reconfiguramos las narrativas respetando la voz de cada participante. En la temporalidad, encontramos las experiencias pasadas, presentes y sus expectativas personales y profesionales; en la socialidad suben a escena diferentes protagonistas que compartieron la vida de cada participante, y en la espacialidad se revelan los lugares donde cada estudiante habitó, estudió, y reside, trabaja y se forma como docente en el presente. En nuestro interés por interpretar las biografías escolares de este grupo de practicantes del Profesorado de Inglés, el paisaje no se puede analizar separadamente porque son sus tres componentes entramados los que van dejando huellas en todo el trayecto vivido. Mediante el trabajo hermenéutico realizado fuimos entretejiendo las voces de cada participante con la de la investigadora logrando un análisis que mantiene la frescura y naturalidad de quienes relatan sus vivencias.

En nuestra investigación conceptualizamos por un lado, el paisaje común de quienes inicialmente deseaban ser docentes -amor por la docencia- y por el otro, de quienes comenzaron la carrera solo por gusto por el idioma, sin estar interesados en la docencia huellas impregnadas por el gusto por el idioma inglés. De esta manera, salimos en busca de respuestas a las preguntas que guiaron nuestra investigación: ¿cuáles son las buenas enseñanzas que han dejado su huella en la biografía del grupo de residentes del Profesorado de Inglés de la UNMdP?, ¿de qué manera caracterizan estas enseñanzas?, ¿cómo se manifiestan en su práctica en el aula esas buenas enseñanzas experimentadas? y ¿cuál es la impronta que dejan en la biografía escolar de cada practicante? A continuación, nos zambulliremos en las historias de quienes iniciaron sus estudios por amor a la docencia. 


\section{Resultados}

\subsection{El deseo de ser docente}

Podríamos afirmar que el deseo de ser docente está fuertemente marcado por la vocación. Sennett (2009) argumenta que la vocación es la tendencia que siente una persona hacia determinadas actividades, es una inclinación natural que, en ocasiones, desde una edad temprana, se revela. Las personas no tienen una sola vocación, agrega él, sino que tienen muchas. Esta posibilidad les permite responder a la más adecuada según su situación y el lugar donde se encuentren. En las historias que co-construimos en el primer momento de la investigación notamos que el deseo de ser docentes nace desde el interior del grupo de participantes; sin embargo, a lo largo de su biografía escolar ha sido alimentado por las distintas circunstancias y experiencias que atravesaron. Observamos también que este deseo se fue nutriendo por el gusto por la lengua inglesa, que incide directamente con la elección del Profesorado de Inglés. Nuestros participantes afirman:

- Joy: "Siempre me gustó enseñar y, antes de comenzar la carrera, había tenido estudiantes de Francés e Inglés en casa".

- Mercedes: "[...] en sí, a mí me gustaba el hecho de enseñar, o de ayudar a los otros a que entiendan. O sea, en la escuela era la típica que "iay Mer! no entiendo, explicame" y bueno, ahí iba y... ayudaba todo lo que podía. En cualquier materia".

- Marian: "Elegí la carrera del Profesorado de Inglés porque siempre he sentido afinidad por aprender el idioma y por enseñar".

- Vera: "Considero que las materias [del Plan de Estudios] en sí mismas influyeron en mi decisión final de estudiar una carrera docente, quería explorar la docencia. Siempre sentí un mayor interés por las materias humanísticas que por las exactas. Uno de los factores determinantes en la elección de la carrera fue la inquietud de seguir estudiando un idioma que disfrutaba aprendiendo".

\subsection{Amor por la docencia}

Al reflexionar acerca de la buena enseñanza y cómo ha influido en su biografía escolar y su formación inicial, Marian, Mercedes, Vera y Joy, quienes estaban seguras de iniciar una carrera docente, argumentan que las huellas del pasado han contribuido en su formación profesional. En estas trazas, se pueden identificar experiencias que las participantes buscan repetir o evitar. Marian evoca a sus docentes que se preocupaban por "crear un bienestar emocional en sus clases, un clima de trabajo propicio para poder trabajar y aprender" (RE), 
por quienes están comprometidos con la materia y con el estudiantado, con quienes se apasionan por la enseñanza y traen a la clase temas de interés para sus estudiantes. Mercedes recuerda a quienes se esforzaron por "crear buenas relaciones con su alumnado posibilitando una cercanía más cálida y más humana" (RE), y fomentaron buenos valores y actitudes positivas hace el aprendizaje. Vera valora a quienes supieron guiar a sus estudiantes a "superarse a sí mismos" (RE) y fomentan el gusto por el idioma para lograr que "la experiencia de aprender un idioma sea agradable más allá de nuestras expectativas" $(\mathrm{RE})$, como también a quienes logran "ponerse en el lugar del alumnado [...] acompañarlo y ayudarlo a reflexionar sobre su práctica" (RE). Joy, por su parte, opina que "la buena actitud [...] de algunas de sus profesoras [de la universidad] influyen positivamente en mi [su] forma de enseñar" (RE), que el reconocimiento por parte del docente del esfuerzo y la dedicación del estudiantado "da a este último una profunda satisfacción de saberse respetado y valorado, no solo como educando, sino también como ser humano" (RE).

Este grupo de residentes caracterizan las enseñanzas a través de los recuerdos de sus docentes y ejemplifican esas experiencias de la siguiente manera: Marian evoca a una profesora del Área Cultural del Profesorado. Asegura que la admira por su gran conocimiento en la materia y la pasión con la que prepara y da sus clases, se preocupa por el aprendizaje del estudiantado, responde dudas por correo electrónico de manera inmediata "es increíble cómo puede hacer que una clase de cuatro horas pase volando y realmente aprendí muchísimo" (EB). También menciona otra profesora que enseña en el Área de Habilidades Lingüísticas a quien rememora por haber sido muy afectiva y comprensiva y por la forma en que "involucra a sus estudiantes" en sus clases "uno se siente que ella nos tiene en cuenta" (GF). También trae a su memoria su profesor de matemáticas del secundario, quien prefería conversar en la clase con el alumnado acerca de todo tipo de temas, no solamente de su materia, sino de la vida, generando así un vínculo especial con el grupo. Asimismo, despierta en sus recuerdos la cena que realizó una docente del profesorado, a modo de cierre de la cursada; valora mucho esos encuentros porque permiten que el alumnado conozca a sus docentes desde otro lugar.

Vera recuerda sus clases de Literatura del profesorado, en la que los miembros de la cátedra "instaban a sus estudiantes a descubrir paso a paso la riqueza de los textos literarios y ofrecían herramientas para lograrlo" (RE), como también recuerda a su tutora de una de las residencias, quien la acompañó y la ayudó a reflexionar sobre su propia práctica produciendo así una "experiencia enriquecedora, un ejemplo que intento seguir con mis estudiantes" (RE). 
Mercedes recuerda especialmente a su profesor de Filosofía del secundario. Relata que el estudiantado podía notar su interés en el alumnado "como personas" (RE), en lo que sentían y pensaban, "siempre nos animaba a pensar y a analizar todo críticamente, y a que tengamos en cuenta que nuestras opiniones y creencias eran importantes y debían ser respetadas. También era muy dedicado en cuanto a la preparación de sus clases [...] reconocido y admirado por muchos de nosotros" (RE). Además rememora docentes del profesorado de quienes, asegura haber rescatado actitudes positivas "la actitud siempre, más que decir una técnica que usa o un tipo de actividad que da" (EB). Evoca a [nombre del docente del Profesorado de Inglés] especialmente, en el tipo de relación familiar que puede establecer con el alumnado, haciéndolos sentir muy cómodos. Asevera que [dos docentes del Profesorado de Inglés] la hacían sentir lo suficientemente cómoda como para participar en las clases, sin temer expresarse libremente, "no se... tenían algo que hacía que me anime a hablar" (EB). También tiene recuerdos de [nombre del docente del Profesorado de Inglés] por quien siente admiración ya que notaba el gusto con el que daba sus clases "lo disfruta" (EB). Opina que es muy exigente, pero en "esa exigencia está lo que espera de vos [...] cree en sus estudiantes, en que pueden... en que pueden mejorar [...] me gusta de ella el gusto que tiene por el conocimiento que tiene y cómo lo refleja y comparte" (EB).

Finalmente, Joy relata una experiencia que, señala, jamás olvidará. Cuando finalizó la cursada de una materia del Área de Fundamentos Lingüísticos, la docente a cargo la recibió "con los brazos abiertos diciendo en voz alta, llena de felicidad y orgullo, que yo había logrado la promoción" (RE). Destaca así que esta actitud de la profesora dejó en ella esta "huella inolvidable que pude sentirme acompañada por ella en el difícil proceso de aprendizaje [...] su mensaje implícito fue que yo podía." (RE).

Así encontramos en la biografía escolar de este grupo de participantes marcas de buena enseñanza que han dejado sus docentes. En una primera lectura observamos que estas trazas están relacionadas con la actitud de docentes, algunas signadas por el afecto y otras por el intelecto. Estas trazas reveladas son lo que Alliaud denomina "secretos de fabricación" (2017, p. 41), refiriéndose a lo que se encuentra en lo más íntimo del acto de enseñar, a una especie de vibración especial de la que son portadores los profesores y profesoras. Estos secretos se van manifestando en la práctica, a medida que van enseñando. Están entretejidos en una "rara formula (de métodos, técnicas y modos de actuar)" (Alliaud, 2017, p. 41) que va dejando su traza a medida que se enseña y tenderá a prevalecer impregnada en el alumnado. Resumimos, a continuación, las marcas halladas: 


\subsection{Actitud afectiva}

Generan bienestar emocional; promueven buenas relaciones en el aula; crean buenos vínculos con el estudiantado; posibilitan una cercanía más cálida, humana y abierta; son afectuosos y comprensivos; hacen que el alumnado se sienta respetado, valorado y cómodo en la clase; demuestran su interés por el grupo de estudiantes como personas logrando así empatía.

\subsection{Actitud intelectual}

Originan un clima propicio de trabajo y aprendizaje; fomentan buenos valores y actitudes positivas hacia el aprendizaje; guían al estudiantado a superarse a sí mismo; inspiran el gusto por el idioma; reconocen el esfuerzo que el alumnado realiza; acompañan al estudiantado en el aprendizaje alentándolo a reflexionar; animan a pensar críticamente tratando temas de interés; valoran las opiniones y las creencias de otros; alientan al estudiantado a alcanzar sus logros; son dedicados, reconocidos y admirados; están comprometidos con la materia y con el alumnado al que valoran; demuestran pasión por lo que hacen y disfrutan enseñar; sienten gusto por el conocimiento y lo comparten; creen en sus estudiantes y les exigen; involucran al alumnado en sus clases; están disponibles para responder preguntas fuera de la clase y se preocupan por el aprendizaje de sus estudiantes.

\subsection{Análisis de los resultados}

\subsubsection{Acerca de la actitud afectiva}

Los aportes del grupo de residentes nos presentan hallazgos significativos desde un camino más afectivo y emocional, el cual transitan en paralelo con las conceptualizaciones teóricas formuladas en la literatura pedagógica, básicamente en la urdimbre intelecto afecto (Porta y Flores, 2017). La sabiduría que corre en el dominio práctico de la enseñanza es muchas veces sedimento de teorías adquiridas, otras, producto de vivencias escolares y personales. En todos los casos, su presencia en la actuación docente es viva, por lo que vale la pena hacer el esfuerzo por recuperarlas. Quienes se preocupan por sus estudiantes como personas, respetan y crean vínculos que fortalecen el aprendizaje. Este "amor pedagógico" (Day 2006, p. 43) consiste en el instinto de cuidar, apoyar y ayudar al estudiantado, y esta cualidad es la amorosidad sin la cual su trabajo pierde el significado, la "amorosidad no solo para los alumnos y alumnas sino para el propio proceso de enseñar" (Freire, 2004, p. 63). La 
complejidad del afecto demanda una elevada capacidad de empatía (Porta y Flores, 2017), que implica ser capaz de percibir la realidad del otro, así como también sentirla.

Davini (2015) explora y desmenuza detalladamente los componentes de la motivación, especialmente los que se relaciona con comunicarse en forma personalizada (Davini, 2015). La autora sostiene que quienes ejercemos la docencia tenemos un grupo que atender, pero no debemos olvidar que la clase la forman individuos con sus propias expectativas, dificultades y necesidades. Agrega que el estudiantado aprecia el intercambio personal, ser reconocido como sujeto y valorado tanto ante las dificultades como en los logros, y tiende a interesarse más por la clase cuando también se lo identifica de forma individual. La autora también hace alusión a incluir la emoción en la enseñanza:

Cualesquiera sean los contenidos, incluir la emoción en la enseñanza impulsa la motivación, implica plantear desafíos, incorporar los intereses del alumnado, apostar a que imaginen ideas y proyectos propios, apoyarlos para superar el miedo y la inseguridad, facilitar distintas formas de expresión de sus ideas y sentimientos. (Davini, 2015, p. 74)

El interés por aprender pone en movimiento la emoción y los sentimientos, va de contramano con la rutina y el aburrimiento, agrega la autora.

\subsubsection{Acerca de la actitud intelectual}

Nuestros participantes destacan "una cultura de las prácticas de la enseñanza que privilegia el pensar en el aula" (Litwin, 1997, p. 85), la enseñanza para la reflexión, el desarrollo del pensamiento crítico (Canagarajah, 2003), la comunicación en la clase reflexiva y la dimensión moral de la enseñanza (Litwin, 1997) que nos remite nuevamente a la buena enseñanza como práctica reflexiva (Jackson, 1999) permitiendo amalgamar el compromiso de la buena enseñanza con el pensamiento y la comprensión. Retomamos así la conceptualización que el Grupo de Investigadores en Educación y Estudios Culturales (GIEEC) ha denominado huellas de la buena enseñanza, que se refiere a esas marcas profundas en la biografía escolar que dejan los mentores y mentoras y que subsisten en la actualidad en el profesorado de la universidad (Porta y Sarasa, 2014).

El grupo de residentes recuerda docentes que acompañan al estudiantado en el aprendizaje y ayudan a reflexionar. En las prácticas cotidianas y en la literatura académica, el concepto de reflexión no se presenta como unívoco. En este término conviven significados 
que dan lugar a prácticas diversas e incluso contradictorias (Edelstein, 2015). Entre ellas, interesa valorar las que conciben la reflexión como reconstrucción crítica de la experiencia individual y colectiva, lo que implica volver sobre las situaciones, a la propia actuación y supuestos acerca de la enseñanza (Edelstein, 2015). De esta manera, la reflexión requiere de diálogo, debate y demanda de contraste intersubjetivo y plural. "El tiempo de reflexión crítica y colectiva es esencialmente diferente de aquel del que se pretende dar cuenta" (Edelstein, 2015, p. 134).

Barboni y Porto (2008) hacen alusión al pensamiento crítico como "aquel que analiza, evalúa y transforma al pensamiento mismo para mejorarlo" (p. 6). Las autoras sostienen que el pensamiento crítico transforma, por cuanto el alumnado piensa de forma más amplia y sistemática, y como consecuencia logra atravesar niveles más elevados (Barboni y Porto, 2008). Aseveran que enseñar a pensar en la escuela requiere de una voluntad conjunta entre todas las personas actoras de la educación que apunte a implementar propuestas y estrategias, materiales didácticos, contenidos y técnicas, que promuevan el desarrollo del pensamiento crítico "a través de la focalización en habilidades lingüísticas críticas y culturalmente relevantes (lectura, escucha, escritura, habla)" (Barboni y Porto, 2008, p. 36).

Asimismo, las autoras afirman que "la integración de pedagogías de este tipo en las prácticas áulicas [sic] diarias en forma deliberada, explícita y continua posibilita el desarrollo de la autonomía" (Barboni y Porto, 2008, p. 36), como también fomenta la reflexión, el pensamiento crítico, el diálogo que impulsa el intercambio de ideas, la colaboración ${ }^{5}$ y cooperación, el respeto y la genuina comprensión mutua. El pensamiento crítico promueve el progreso (Sennett, 2009), el sociólogo afirma que volver una y otra vez a la acción permite la autocrítica. Se trata de un progreso que no es lineal, sino que se construye moviéndose de manera irregular, que inspira el despertar de una idea, que conduce a lo sublime como un "horizonte ilimitado" (Sennett, 2009, p. 138).

Adentrándonos más específicamente en la enseñanza de la lengua extranjera, recordemos que fomentamos el gusto por el idioma promoviendo la enseñanza a través del contenido, no como lenguaje vacío, carente de significación (Dörnyei, 2009), sino que lo hacemos valorando y focalizando en la diversidad individual, considerando que cada

\footnotetext{
$5 \mathrm{Al}$ respecto dice Alliaud "el desafío que hay que enfrentar para saber y poder trabajar colaborativamente consiste en aprender a poblar el espacio público -aquel que se comparte con otros- y asumir colectivamente las problemáticas que la tarea que nos une -la enseñanza- nos genera [...] Si bien consiste en un intercambio que puede compensar aquello de lo que carecemos individualmente y, por lo tanto beneficiarnos, en muchos casos es difícil o exigente porque implica entenderse, comprenderse, respetarse..." (2017, p. 117).
} 
estudiante aprende de diferentes maneras ya que tienen potenciales distintos. La enseñanza debe tomar estas diferencias en cuenta, en lugar de forzar al alumnado a encajar en un solo molde. El lenguaje debería servir como medio de desarrollo de habilidades de pensamiento, como el crítico y el creativo (Jacobs y Farrell, 2001). También fomentamos el gusto por el idioma cuando enseñamos con pasión. Day (2006) se refiere a la pasión que los profesores y profesoras sienten y manifiestan por su enseñanza y por la disciplina (Álvarez y Porta, 2014). El principal aporte que podemos hacer a la formación de nuestros estudiantes es trasmitirles pasión por el conocimiento (Zabalza, 2007), que lleguen a "valorar la importancia de ir avanzando cada vez más en el conocimiento para poder desarrollar una acción profesional más rica y efectiva" (Zabalza, 2007, p. 197). Para ello es preciso que quienes educan sientan esa pasión y también que estén dispuestos a compartirla.

Cuando el grupo de residentes aluden a la valoración de creencias y opiniones del estudiantado, nos remitimos al principio de posibilidad acuñado por Kumaravadivelu (2001) que promueve una pedagogía de posibilidad que empodera al estudiantado. Este principio sostiene la necesidad de desarrollar teorías, formas de conocimiento y prácticas sociales que vayan de la mano con las experiencias que cada individuo trae al contexto pedagógico, todas ellas moldeadas no solo por la enseñanza y el aprendizaje previo, sino por el entorno social en el cual se han desarrollado como sujetos. Asimismo, Bain (2007) destaca a los buenos profesores y profesoras, quienes aprecian el valor individual de cada estudiante, ya que comprenden las fuerzas externas que pueden determinar el éxito académico, animándolos también a ser reflexivos y francos.

Finkel (2000) sintetiza lo expuesto en los párrafos precedentes cuando revela la importancia de lo que se es y de lo que se hace -más allá de lo que se dice- cuando un docente busca promover que sus estudiantes se interesen por el conocimiento, que lo ame y que lo utilice de manera honesta. La actitud del docente, el trato, la preparación, la sensibilidad, la dedicación, la escucha, la observación, la puntualidad y el ejemplo son formas de enseñanza no menos explícitas que la palabra; es decir, no solo se da clase en voz alta. Veremos, a continuación, las primeras conceptualizaciones que se desprenden de una mayor, de la actitud docente. Se trata de una actitud motivadora, dedicada, empática, sensible, flexible y abierta, que incluye emoción y afecto, que promueve el gusto por la disciplina, que valora las creencias y opiniones, promueve la reflexión y el pensamiento crítico. Estas cualidades que los residentes encontraron en quienes participaron activamente en su formación nos conducen a nuevas conceptualizaciones que se desprenden de una 
actitud que logra motivar al alumnado desde distintos lugares, desde lo afectivo y desde lo intelectual.

El grupo de residentes que participaron en esta investigación logra zambullirse en su biografía escolar encontrando importantes trazas que sus docentes han dejado, reconociéndolas como marcas que afloran en sus propias prácticas. De esta manera, Marian, Vera, Mercedes y Joy ven reflejadas en su espíritu de educadoras esas huellas que sus docentes han dejado en sus biografías escolares; interpretamos seguidamente, cómo se manifiestan en su práctica en el aula.

Marian asegura que durante sus residencias ha "tratado en todo momento de tener en cuenta el ambiente de trabajo, buscando crear bienestar en el alumnado, para que se sientan a gusto durante mis [sus] clases" (RE). Cree firmemente que el estudiantado debe sentirse cómodo en el aula y con su docente para así "comprometerse con las actividades de aprendizaje. Lograr un buen clima en la clase y buenas relaciones en el aula influye decisivamente" (RE) en el proceso de enseñanza y aprendizaje. Efectivamente, Marian genera un ambiente ameno, abierto, y dinámico en el aula promoviendo una actitud flexible, desde el alumnado hacia ella y viceversa. Estas cualidades permitieron develar el cariño que sus estudiantes le brindaban, generándose un lazo de afecto recíproco (RET). Marian disfruta enseñar (EF) y el alumnado lo percibe (RET).

Por su parte, Vera acompaña a cada estudiante acercándoseles, alentándoles a seguir adelante, a superarse, guiándoles en las tareas. Se muestra interesada en sus progresos, en ocasiones, hasta interactúa con el grupo de estudiantes de manera maternal (RET). Ofrece textos auténticos, que motivan aún más a sus estudiantes, seguidos por actividades que promueven la necesidad de usar la lengua extranjera en el aula. (RET). Mercedes llega al aula por lo menos diez minutos antes del inicio de la clase, prepara todo el material -audio, video, fotocopias, marcadores para pizarra de diferentes colores; todo lo que va a usar ese día está prolijamente organizado. Espera a sus estudiantes parada delante del escritorio. Ellos van llegando lentamente. Son adultos, vienen de otras clases en la universidad o de trabajar (EF). Observamos que ha construido una agradable relación con ellos, es flexible y abierta, dispuesta a brindar las respuestas que le demandan. Genera una actitud positiva hacia el aprendizaje, trae material útil y específico para el grupo -carrera Licenciatura en Turismo- promueve la participación activa del alumnado en todas las actividades. Alienta la reflexión mediante preguntas o el análisis del material de clase (RET). En ocasiones adopta 
posturas o actitudes de sus docentes, sobre todo al tratar de mantener la clase tranquila $(\mathrm{EF})$.

Por su lado Joy deja expuesta toda su afectividad en las clases (RET). Recibe a sus estudiantes en la puerta del aula, saluda a cada uno de ellos con un beso. En ocasiones abre sus brazos para recibirlos. Valora mucho el esfuerzo que hacen para asistir a la clase y les agradece su presencia (EF). Desea que sus estudiantes se sientan valorados y respetados. Logra un clima de clase relajado, afectuoso y activo (EB - RET), "si noto tensión me detengo, me siento con ellos y pregunto la causa. El debate grupal siempre me ha sido muy útil" (EB). Alienta permanentemente utilizando frases que motivan al estudiantado a seguir adelante (EF). "Mi motto es que todos estamos en el aula para aprender. Ellos de mí y yo de ellos. En un marco de mutuo respeto sus estudiantes comienzan a exponer oralmente" (RE). Trata de no corregirlos en la producción oral para no exponerlos ante sus pares (RE), busca indicarles cuál sería la forma correcta de expresarse y lo hace de una manera sutil. "Siempre me pregunto qué más puedo yo darles aparte del idioma inglés. Desde dónde puedo yo llegarles para incentivar sus deseos de aprender [...] trato de hacerles pensar" (EB). Contagia su entusiasmo y el estudiantado participa activamente (RET). Les ayuda permanentemente alentándoles a superarse. Sonríe, siempre sonríe (RET).

Encontramos así huellas reflejadas en sus prácticas iniciales, también referidas a la actitud docente:

\subsubsection{Actitud afectiva}

Crean lazos afectivos con sus estudiantes, generan bienestar haciendo sentir cómodo al alumnado, son afectuosos, valoran y respetan al estudiantado, y logran una relación flexible y abierta en la clase.

\subsubsection{Actitud intelectual}

Alientan a seguir adelante y a superarse, promueven la reflexión y el pensamiento crítico, contagian entusiasmo, buscan lograr una clase tranquila, instalan un clima de clase relajado pero activo, disfrutan enseñar, inspiran una actitud positiva hacia el aprendizaje (incentivan en deseo por aprender), acompañan al estudiantado en el proceso de aprendizaje acercándose y guiándoles, se muestran interesados por su progreso, motivan el aprendizaje (por ejemplo, ofreciendo textos de interés) e involucran al grupo de estudiantes activamente en la clase. 
La vida de las representaciones se revela como memoria impregnada en el cuerpo. (Moscovici y Hewstone, 1986), toma forma de imagen y tiene la propiedad de poder intercambiar lo sensible y la idea, la percepción y el concepto con un carácter simbólico y significante, carácter constructivo, autónomo y creativo. Para Bourdieu (1996), las representaciones, creencias, pensamientos y percepciones de los agentes varían y se organizan según su posición en el campo social y según su incorporación de las estructuras sociales en el habitus. Estas experiencias implícitas, a veces no verbales y representativas del dominio de las prácticas del campo (Bourdieu, 1996), son las que nuestros participantes traen a las prácticas iniciales y se revelan en el aula. Así, los habitus individuales residen en la singularidad de las trayectorias sociales y personales, en función de experiencias anteriores de miembros de un mismo grupo, pero, de alguna manera se entrelazan en un paisaje común inducido por su propia práctica.

\subsubsection{Impronta de las huellas que dejaron los maestros en las biografías escolares}

Luego del análisis precedente, nos sumergiremos en el rastro que estas huellas dejan en la biografía escolar del grupo de practicantes. Nuestro objetivo estuvo ligado a la búsqueda y localización de la impronta misma en el relato de quienes indicaron, desde un principio, su deseo de ser docentes. Nos interesa en este punto otorgarles la voz y dejarla vibrar:

\section{Joy}

Todos mis docentes [...] influyeron en mi carrera. De los buenos, excelentes alguno de ellos, aprendí lo que debo hacer. De los otros, lo que no debo ni quiero hacer con mis estudiantes. La universidad es un pequeño universo y podemos encontrar todo en él. (EB) Me siento una buena futura docente cuando puedo reconocer en mis estudiantes el brillo de la comprensión. Cuando descubren por sí mismos luego de ser guiados por mí. Cuando me hacen saber que me equivoqué o se aburren. Cuando escucho sus voces en un marco de respeto y afecto. Disfruto ser docente dentro y fuera del aula. Participo activamente de la vida de mis estudiantes. Ellos saben que cada uno es importante para mí. El objetivo primordial es que ellos sepan o reconozcan el valor esencial de la cultura. (EB)

Cuando un estudiante se siente respetado y escuchado, respeta y escucha [...] el clima de la clase debe ser ameno, relajado, afectuoso y activo [...] lo que mejor funciona en mis prácticas es el afecto, el lazo afectivo que logro con mis estudiantes y la pasión con que 
imparto la materia. Amo tanto el inglés que los chicos se contagian. Así nace la magia y logro que trabajen, que lo intenten y si tengo suerte, que aprendan. El saber que ayudando a mis estudiantes a pensar, comprender y aprender les abrirá más posibilidades en la vida, me motiva e impulsa cada día a ser mejor docente. Pienso que buscando y aprendiendo de los que saben más que yo, me da la posibilidad de mejorar. (EB)

\section{Marian}

Creo que el estudiantado debe sentirse cómodo en la clase y con su docente, para lograr un fuerte compromiso en las actividades de aprendizaje, lograr un buen clima y buenas relaciones en el aula, influye decisivamente en lo que queremos conseguir con nuestro trabajo educativo (RE). Cada docente tiene que, ante todo, involucrarse con el grupo que está enseñando, no solamente ser el que tiene conocimiento y lo tiene que transmitir, sino saber también qué gustos tienen sus estudiantes, cuáles son sus preferencias; desde su lugar puede enseñarles y también interactuar con ellos [sic], que no sea solamente él quien enseña y el alumnado el que reciban sino que sea algo más que eso. (GF) Para planificar mis primeras clases tuve ayuda de la directora/dueña del instituto, que también estudió en la UNMdP. Aprendí mucho durante esa primera experiencia [...] como también de mis compañeras de trabajo con las que compartí material, experiencias y técnicas. [...] Siento mucha motivación al preparar mis clases porque disfruto enseñar valorando a mis estudiantes [...] trato de hacer las clases dinámicas y variadas. (EB)

\section{Mercedes}

Cuando ves que algo que vos... con lo que vos los ayudaste, le sirve para hacer algo y que lo recuerda [...] la recompensa está en... en eso, en la satisfacción de saber que... que podes ayudar al otro a creer en sí y a superarse [...] y en establecer un vínculo de alguna forma, una relación con esa persona que está ahí, que es una persona [...] Me parece que... que eso es lo que quiero tener también en algún momento [...] Cuando sentís esa satisfacción o recompensas para... la persona a la que le estas enseñando, y para vos misma, la recompensa de cómo te sentís, creo que ahí te das cuenta de que vale la pena seguir por ese lado...(EB) Me gustaría poder participar de su vida, o sea llegar... por esto del vínculo que me parece que apunto a eso [...] primero son personas y después estoy ahí para ayudar. (EB).Mi intención es valorar las capacidades y esfuerzos del estudiantado más allá de los resultados finales (RE). [...] involucrar los intereses del alumnado en el aula, y para 
eso hay que estar muy atento a cada uno, qué capacidades tiene y su forma de aprender. (GF)

\section{Vera}

El aprendizaje frente al aula fue y es continuo y cada nueva experiencia me lleva a reflexionar y a buscar nuevas respuestas. (EB) Mi motivación al enseñar es poder compartir un conocimiento que abre puertas al futuro tanto a nivel personal como profesional. Disfruto ser docente al ver los logros de mis estudiantes y el interés por seguir aprendiendo. Mi motivación para actualizar conocimiento y superarme en mi práctica docente son los grupos de estudiantes y sus expectativas. Considero que la formación integral del estudiantado depende del compromiso que cada docente asuma para capacitarse y poder así responder a las inquietudes y necesidades de sus estudiantes. Dos de los recursos más importantes que contribuyen a mejorar mis prácticas son el diálogo con colegas y la posibilidad de incorporar nuevos enfoques y metodologías en mis clases. (EB)

En la Figura 1 representamos los rasgos que logramos encontrar en la biografía escolar de nuestros participantes y que están impregnados en ellas en forma de huellas: 
Figura 1. Rasgos de la biografía escolar de las personas participantes del Profesorado de Inglés de la Universidad Nacional de Mar del Plata

\section{AMOR POR LA DOCENCIA}

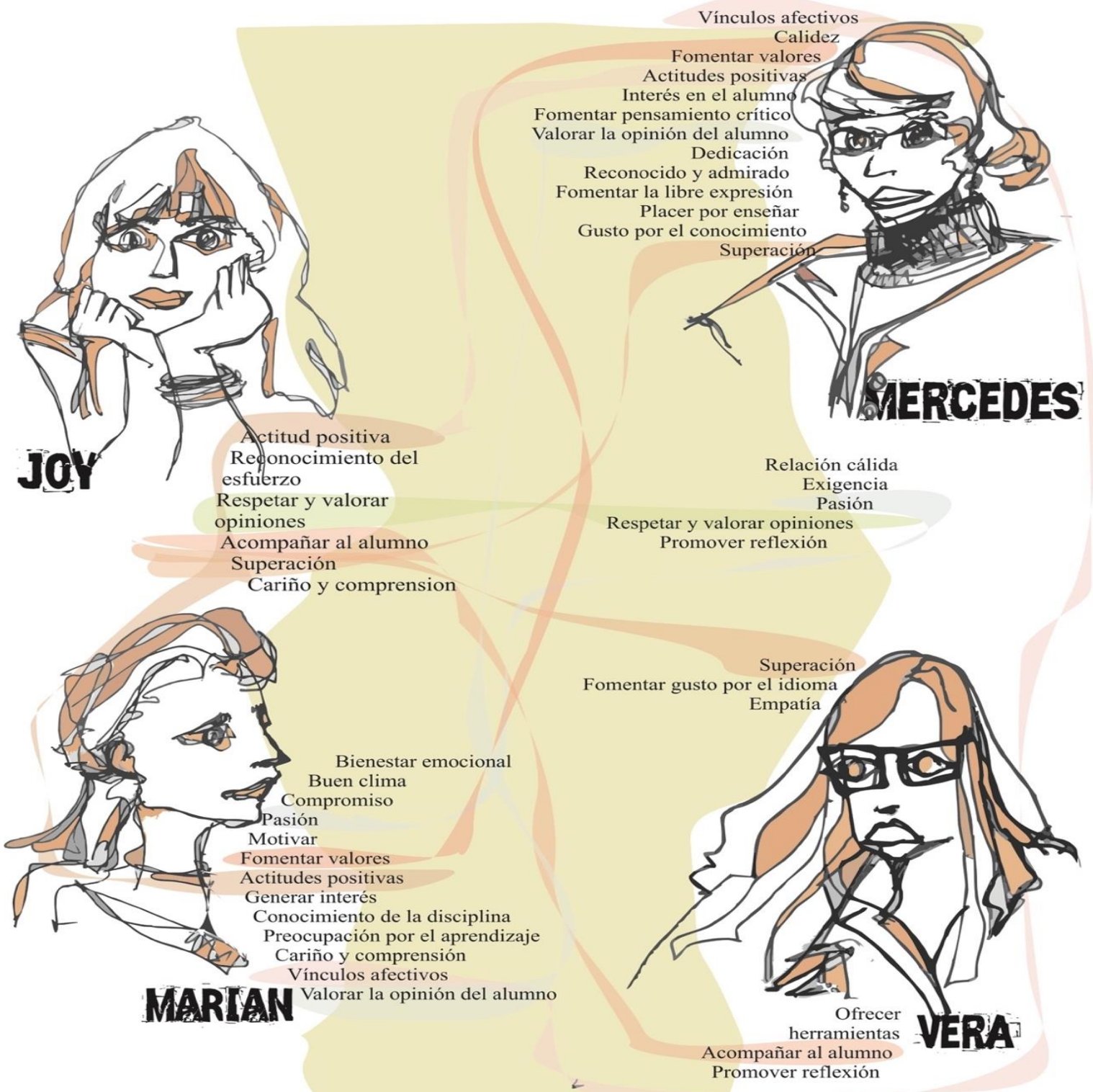

Fuente: Elaboración propia (2017). 


\section{Conclusiones}

El saber que proviene de la experiencia está encarnado en los cuerpos de quienes lo reciben y toma forma de quienes reconocemos como maestros y maestras en el oficio de enseñar. Se diferencia de los conocimientos prácticos y no se produce mediante la acumulación de teorías, sino que se revela a través de las experiencias y las situaciones cotidianas que, por algún motivo, toman un carácter extraordinario. Se trata de vivencias que aportan un significado especial para quienes las protagonizaron ya sea por el efecto que produjeron o por sus implicancias en la forma de pensar la educación. Este saber alude a la pasión, por lo que reclama un lenguaje peculiar para elaborar el sentido de lo que nos pasa (Edelstein, 2015), no puede ser anticipado, no tiene que ver con el tiempo lineal de lo previsible, de la prescripción o de la predicción, solo una mirada en retrospectiva puede explorar sus sentidos. Cada individuo revela en su accionar cotidiano el sistema social en el que se sumerge y lo hace vívido en este pasaje semiótico hacia el relato. La retórica de su vida revela una estructura social, un sistema que se hace presente en la biografía haciendo voz de su verdad al interpelar su propia experiencia.

Luego de la inmersión recursiva en los textos de campo sostenemos, sin duda alguna, que el grupo de estudiantes del Profesorado de Inglés que participó en la investigación se constituyó desde las experiencias protagonizadas a lo largo de sus vidas, entre las cuales el paso por las distintas instituciones educativas es parte de uno de los sucesos, tal vez, más extenso y de mayor permanencia. Las vivencias en cada biografía no son asépticas, sino que van dejando trazas que luego se manifiestan en forma de creencias y valoraciones acerca de la realidad en que se inscriben moldeando así la práctica docente.

Propusimos al grupo de residentes narrar en sus propias vivencias, cuestiones que surgen desde el quehacer cotidiano. El acto de contar alguna experiencia de su biografía escolar los alentó a buscar en sus recuerdos y realizar una elaboración personal en la que deben tomar una posición y contarlo desde su yo, y al hacerlo se reconocieron a sí mismos en aquello que estaban contando. Las narraciones, así entendidas, más que prescribir cómo deben actuar quienes ejercen la docencia, inspiran cursos de acción, abren interrogantes y promueven respuestas variadas; provocan, sorprenden e intrigan; nos dejan pensando, tanto a quienes las narran como a quienes las escuchan o leen. De esta manera, para quienes eligen el Profesorado de Inglés como actividad profesional, las biografías escolares constituyen una mochila de experiencias listas para usar al momento de resignificar y de poner en práctica la formación recibida. Estas experiencias van cobrando vida y se traducen 
en actitudes y supuestos a partir de los cuales el grupo de practicantes reacomoda las decisiones tomadas en el aula y fuera de ella. La biografía escolar como paso por la escuela representa, para quienes desean ser docentes, un torrente de experiencias personales que necesitamos considerar al momento de definir su formación profesional.

En todo el proceso de investigación surgieron múltiples temáticas que recuperamos de la teoría, de las biografías escolares del grupo de practicantes y de la interacción con los textos de campo. Decidimos resumirlas aquí en tres ejes amplios: acerca de sus docentes, acerca de las instituciones educativas y acerca de sí mismos.

Acerca de sus docentes: En los relatos de las personas participantes encontramos una fuerte presencia de las enseñanzas que dejaron sus docentes, las cuales se manifiestan en las prácticas iniciales, identifican los rasgos afectivos y profesionales de sus educadores ya sea aceptándolos o cuestionándolos. Los atributos asignados a sus docentes están muy vinculados, por un lado, con las relaciones interpersonales que lograron establecer dentro del aula y fuera de ella -como, por ejemplo, el trato y la atención brindada en forma individual y grupal- y, por el otro, con la forma de enseñar, su excelencia académica y su pasión profesional. Emergen en sus relatos los nombres de aquellos docentes que los marcaron en las decisiones tomadas para acciones de índole pedagógica, personal e incluso para la elección de sus carreras. Luego de reflexionar acerca de sus trayectorias escolares, cada practicante reconoce incuestionablemente la marca que sus docentes les han dejado, la enseñanza implícita o explícita relacionada con el vínculo afectivo que se construyó, el agradable clima generado en la clase, la calidez humana que el docente brindó, el amor revelado por la disciplina, el ánimo de superación que promovió y, sobre todo, la pasión por enseñar.

Acerca de las instituciones educativas: Para incorporar procesos de análisis y reflexión de las prácticas docentes es central contar con condiciones de posibilidad a nivel institucional. En torno a las propuestas de formación inicial y continua, resulta relevante que se instituyan "experiencias anticipatorias" (Edelstein, 2015, p. 201) que habiliten la transferencia a los contextos singulares de trabajo. En las conceptualizaciones que surgen del análisis de los datos obtenidos, las instituciones educativas cobran un rol relevante en la biografía de cada practicante. El paso por los distintos niveles de escolarización se hace visible en algunas biografías como algo que se "disfrutó" y en otras como algo que "cuesta", "duele" y a lo que es "difícil de adaptarse". En ocasiones se refieren a cuestiones académicas y en otras al proceso de socialización en las distintas instituciones por las que pasaron. Esto 
nos lleva a advertir la marca que la cultura institucional deja sobre quienes transitan las instituciones educativas. Las nuevas concepciones acerca de la práctica, los conocimientos y saberes necesarios para ella, traen aparejado un cambio institucional para eliminar las barreras preexistentes en el accionar cotidiano y atender nuevos requerimientos. Quienes participaron de esta investigación lo advirtieron y dejaron traslucir este deseo de cambio.

Acerca de sí mismos: Las evocaciones, apreciaciones y conocimientos de quienes participaron de la investigación se hacen presentes tanto en la expresión escrita (relatos escritos, planes, diarios de clases e informes finales), en la expresión verbal (las entrevistas biográficas, focales y flash) y en las acciones a través del registro etnográfico. Lo que manifiestan da cuenta de sus reflexiones y comprensiones construidas acerca de su propia experiencia social. Los relatos reflejan la presencia de otros sujetos implicados en su biografía -familia, escuela, docentes, pares- la cual revela el carácter social de su formación. Los pares logran ocupar un lugar significativo en algunos testimonios, ya sea de forma positiva o negativa. En las biografías está muy presente el aporte de la familia, sobre todo de los padres y las madres, quienes tuvieron una gran influencia en el grupo de participantes al momento de elegir su carrera, tanto por su intervención directa como por el deseo de que su hijo o hija pueda elegir el proyecto de vida que más le haya atraído, pero siempre alentándoles al ingreso en las aulas de la universidad.

La imagen en torno a sí mismo como profesional está impregnada por las marcas de docentes que nutrieron la práctica inicial de este grupo de participantes. En ocasiones, afloran como rasgos positivos y en otras toman forma de recuerdos de enseñanzas que no quieren reproducir. Expresan que su paso por el Profesorado de Inglés fue una instancia importante de su formación que atesoraron junto con sus experiencias de vida, logrando así una amalgama deseable para proyectarse como profesionales.

Finalmente, la investigación que dio vida a este artículo provocó en sus participantes un profundo proceso de reflexión en el que emergieron aquellas huellas que dejaron sus docentes. Este proceso les permitió reconocer las buenas prácticas heredadas que han quedado tatuadas en sus pieles e identificarse a sí mismos como docentes portadores de huellas. Esta investigación, con su fuerte abordaje metodológico y todos los instrumentos utilizados, puede ser usada por diferentes investigadores con otro grupo de residentes de otros profesorados y propiciar así el análisis reflexivo que esta logró en el estudiantado del Profesorado de Inglés que participó de esta experiencia. 


\section{Agradecimientos}

Nuestra más sincera gratitud al grupo de estudiantes del Profesorado de Inglés que participó en esta investigación y brindó de manera desinteresada su tiempo. Al grupo de doctorandos y doctorandas de Mar del Plata que realizaron su Doctorado en Ciencias de la Educación en la Universidad Nacional de Rosario, compartieron sus experiencias en torno a la investigación biográfico-narrativa y formaron un pilar fundamental para la comunidad narrativa que se construyó en el CIMED (Centro de Investigaciones Multidisciplinarias en Educación) de la Facultad de Humanidades, Universidad de Mar del Plata, del cual somos parte.

\section{Referencias}

Alliaud, Andrea. (2017). Los artesanos de la enseñanza. Acerca de la formación de maestros con oficio. Buenos Aires, Argentina: Paidós.

Alliaud, Andrea. (2010). La biografía escolar en el desempeño profesional de docentes noveles. Proceso y resultados de un trabajo de investigación. En Catalina Wainerman y María Mercedes Divirgilio. (Comps.), El quehacer de la investigación en educación. (pp. 163-178). Buenos Aires, Argentina: Manantial.

Álvarez, Zelmira y Porta, Luis. (2014). Caminos de la indagación sobre la buena enseñanza: Aproximación biográfico-narrativa en educación superior. Revista de educación, 3(4), 75-88.

Bain, Ken. (2007). Lo que hacen los mejores profesores universitarios ( $2^{\mathrm{a}}$ ed.). Barcelona, España: Universidad de Valencia.

Barboni, Silvana y Porto, Melina. (2008). Propuesta didáctica para el desarrollo del pensamiento crítico a través de la clase de inglés en la Educación Primaria Básica. En Una escuela que enseña a pensar. Trabajos premiados (pp. 141-187). Buenos Aires, Argentina: Runa Gráfica.

Bolívar, Antonio, Domingo, Juan y Fernández, Manuel. (2001). La investigación biográficonarrativa en educación. Enfoque y metodología. Madrid, España: La Muralla.

Bourdieu, Pierre. (1996). Cosas dichas. Barcelona, España: Gedisa.

Bruner, Jerome. (1997). La educación, puerta de la cultura. Madrid, España: Visor.

Canagarajah, Suresh. (2003). Resisting Linguistic Imperialism in English Teaching. Oxford, Inglaterra: OUP. 
Caporossi, Alicia. (2009). La narrativa como dispositivo para la construcción del conocimiento profesional de las prácticas docentes. Los dispositivos para la formación en las prácticas profesionales (pp. 107-149). Rosario, Argentina: Homo Sapiens.

Clandinin, D. Jean. Connelly, F. Michael. (1995). Teachers' professional knowledge landscapes. New York, Estados Unidos: Teachers College Press.

Connelly, F. Michael. y Clandinin, D. Jean. (1990). Stories of experience and narrative inquiry. Educational researcher, 19(5), 2-14.

Connelly, F. Michael y Clandinin, D. Jean. (1994). Telling teaching stories. Teacher education quarterly, 21(1), 145-158.

Connelly, F. Michael y Clandinin, D. Jean. (2006). Narrative Inquiry. En Judith Green, Camilli, Gregory and Patricia Elmore (Eds), Handbook of complementary methods in education research (pp. 477-487). Mahawah, NJ: Laurence Erlbam.

Davini, María Cristina. (2015). La formación en la práctica docente. Buenos Aires, Argentina: Paidós.

Day, Christopher. (2006). Pasión por enseñar. La identidad personal y profesional del docente y sus valores. Madrid, España: Narcea.

Dörnyei, Zoltán. (2009). The 2010s Communicative language teaching in the 21st century: The 'principled communicative approach'. Perspectives, 36(2), 33-43.

Edelstein, Gloria. (2015). Formar y formarse en la enseñanza. Buenos Aires: Paidós.

Finkel, Donald. (2000). Teaching with your mouth shut. Michigan, United States: Boynton/Cook Publishers.

Freire, Paulo. (2004). Cartas a quien pretende enseñar. Buenos Aires: Siglo XXI Editores.

García, Marcelino. (2015). Intervenciones disciplinares, experimentación, continuidad, abducción. En Jornadas de Investigadores 2015. Secretaría de Investigación y Postgrado. FHyCS-UNaM Recuperado de https://docplayer.es/86139970-Textoinvestigacion-intervenciones-disciplinares-experimentacion-continuidad-abduccionmarcelino-garcia.html

Hargreaves, Andy. (1996). Profesorado, cultura y postmodernidad. Madrid: Morata.

Jackson, Philip. (1999). Enseñanzas implícitas. Buenos Aires, Argentina: Anorrortu.

Jacobs, George y Farrell, Thomas E. (2001). Paradigm Shift: understanding and implementing change in second language education. TESL-EJ, 5(1). Recuperado de http://tesl-ej.org/ej17/a1.html

Kumaravadivelu, Balasubramanian. (2001). Towards Postmethod Pegagogy. TESOL Quarterly, 35(4), 537-556. 
Litwin, Edith. (1997). Las configuraciones didácticas. Una nueva agenda para la enseñanza superior. Buenos Aires, Argentina: Paidós.

Lortie, Dan. (1975). Schoolteacher. Chicago, Estados Unidos: The University of Chicago Press.

Moscovici, Serge y Hewstone, Miles. (1986). De la ciencia al sentido común. En Serge Moscovici, Psicología social II. Barcelona, España: Paidós.

Polkinghorne, Donald. (1995). Narrative configuration in qualitative analysis. En J. Amos Hatch and Richard Wisniewski (comps.), Life History and Narrative (pp. 5-23). Londres: Falmer.

Porta, Luis y Flores, Graciela. (2017). La hospitalidad en profesores memorables universitarios. Revista de Estudios y Experiencias en Educación, 16(30), 15-31.

Porta, Luis y Sarasa, Cristina. (2014). Resignificar la buena enseñanza desde la voz de docentes memorables en educación superior confrontada con Ortega y Gasset y otros académicos. Profesorado: Revista de currículum y formación del profesorado, 18(1). Recuperado de http://www.ugr.es/local/recfpro/rev181COL6.pdf

Ricoeur, Paul. (2000). Tiempo y narración I. Configuración del tiempo en el relato histórico. Buenos Aires, Argentina: Siglo XXI.

Rockwell, Elsie (2011). La experiencia etnográfica. Historia y cultura en los procesos educativos. Buenos Aires, Argentina: Paidós.

Sennett, Richard. (2009). El Artesano. Barcelona, España: Anagrama.

Taylor, Steven y Bogdan, Robert. (2007). Introducción a los métodos cualitativos de investigación. Buenos Aires, Argentina: Paidós.

Yuni, Jose y Urbano, Claudio. (2005). Mapas y herramientas para conocer la escuela. Investigación Etnográfica. Investigación- Acción. Córdoba, Argentina: Brujas.

Zabalza, Miguel Ángel. (2007). Competencias docentes del profesorado universitario. Madrid, España: Narcea Ediciones. 
Revista indizada en

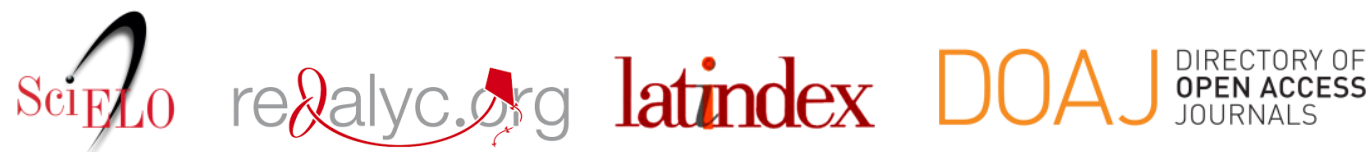

Distribuida en las bases de datos:

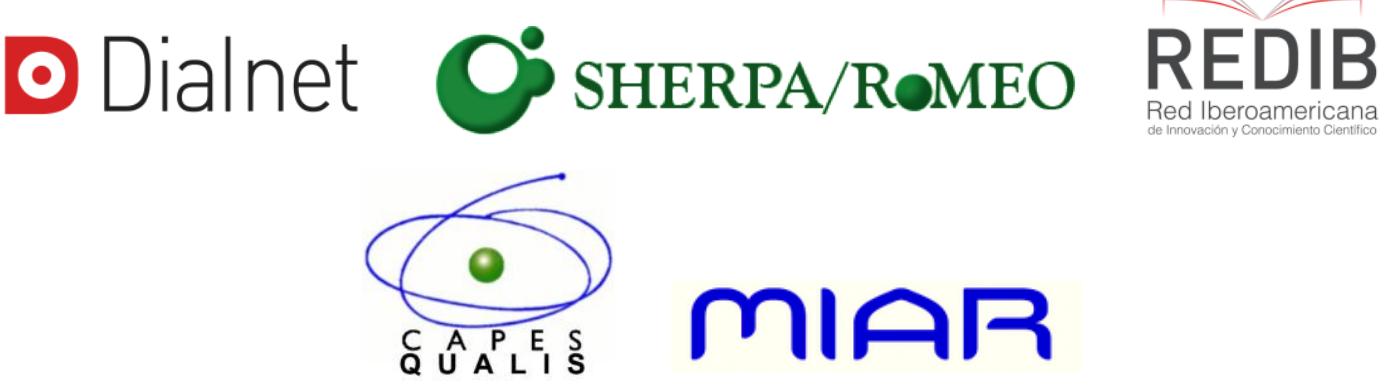

